\title{
Sm-doping effect on optical and electrical properties of $\mathrm{ZnO}$ films
}

\author{
H. Y. He $\cdot$ J. Fei $\cdot$ J. Lu
}

Received: 26 November 2014 / Accepted: 7 January 2015/Published online: 21 January 2015

(C) The Author(s) 2015. This article is published with open access at Springerlink.com

\begin{abstract}
A series of $\mathrm{ZnO}$ : $\mathrm{Sm}$ films with Sm content of $0-1.0$ at.\% were deposited by a chemical solution deposition. The deposited films were characterized by X-ray diffraction, field emission scanning electron microscopy, UVVis and luminescent spectrophotometry, and electrical resistance measurement. The experiments revealed that the Sm doping first increased and then decreased the optical transmittance, band gap, and n-type conductivity with increasing Sm content. The film with the Sm content of 0.75 at.\% showed optimal optical and electrical properties. The maximal band gap widening was about $0.19 \mathrm{eV}$. The resistance decrease of $\sim 20$ times was observed. The photoluminescence measurement indicated that the films showed a strong near band gap emission and a blue-green emission related to intrinsic defect. The refractive index, extinction coefficient, and dielectric constant of the films were calculated with the transmittance and reflectance spectra.
\end{abstract}

Keywords $\mathrm{ZnO} \cdot$ Sm-doping $\cdot$ Transmittance $\cdot$ Band gap $\cdot$ Luminescence $\cdot$ Electrical resistance

\section{Introduction}

Zinc oxide $(\mathrm{ZnO})$ is a wide band gap II-VI semiconductor (3.2-3.37 eV). This material has very attractive properties, including high transparency in the visible wavelength, a high piezoelectric constant, a large electro-optic coefficient [1] and a large exciton binding energy $(\sim 60 \mathrm{meV})$ at room temperature. Many studies have recently focused on $\mathrm{ZnO}$

H. Y. He $(\bowtie) \cdot$ J. Fei $\cdot$ J. Lu

College of Materials Science and Engineering, Shaanxi

University of Science and Technology, Xi' an 710021, China

e-mail: hehy@sust.edu.cn materials because of their potential application in solar cells, gas sensors, piezoelectric transducers and varistors [2-5]. Early studies verified that some dopants, such as Al, In and $\mathrm{Ga}$, can improve the electrical and optical properties of $\mathrm{ZnO}$ films [6-8]. Recently, widening in the band gap of $\mathrm{ZnO}$ produced by $\mathrm{Ti}-, \mathrm{Ca}-, \mathrm{Si}, \mathrm{Sc}$, and Mo-dopants has also been reported [9-14]. Rare earth cations, such as $\mathrm{Tb}$ [15] and Er [16], are more effective. In this work, we focus on the effects of $\mathrm{Sm}$ doping on the optical and electrical properties of the $\mathrm{ZnO}$ films.

\section{Materials and methods}

The starting materials used are all analytic reagents without any further treatment. $0.02 \mathrm{~mol} \mathrm{ZnNO}_{3} 6 \mathrm{H}_{2} \mathrm{O}$ was first dissolved in solution of $40 \mathrm{ml}$ ethanol and $40 \mathrm{ml}$ glycol propylene in glass beaker. Subsequently, the $\mathrm{Sm}_{2} \mathrm{O}_{3}$ for all five samples with Sm content of 0, 0.25, 0.5, 0.75, and 1.0 at.\% were dissolved into $10 \mathrm{ml} \mathrm{HCl}$ in another glass beaker with constant stirring. The Sm cation solution was expanded to $50 \mathrm{ml}$ with ethanol and added into the four $\mathrm{Zn}$ cation solutions at the designed $\mathrm{Sm}$ contents by volume. The mixed solutions were then all expanded to $100 \mathrm{ml}$ with ethanol. After a constant stirring of $10 \mathrm{~min}$ and an aging of $5 \mathrm{~h}$ at room temperature, the solutions were deposited on ultrasonically cleaned glass substrate by dip-coating method. After each coating, the films were dried at $150{ }^{\circ} \mathrm{C}$ for 2-5 min. By repeating such dip-coating and drying processes for six times, the films were finally obtained by calcining the dried films at $450{ }^{\circ} \mathrm{C}$ for $1.5 \mathrm{~h}$.

The phase and structure of the deposited films were identified at room temperature using an X-ray diffractometer (XRD, $\mathrm{CuK}_{\alpha 1}, \lambda=0.15406 \mathrm{~nm}$, Model No: D/Max2200PC, Rigaku, Japan). The morphology of the films were 
analyzed using a field emission scanning electron microscope (EF-SEM, Model No: JXM-6700F, Japan). The film thickness was determined by a film thickness measuring instrument (Model No: CHY-CB, Labthink, Jinan, China). The light transmittance and reflectance spectra of the films were conventionally recorded on UV-vis spectrophotometer (Model No: UV2600, SDPTOP, Shanghai, Chian). The photoluminescence spectra of the films were measured by a luminescent spectrophotometer (Model no: F-4600, Hitachi, Japan). The electrical resistance of the films was measured by a 4-point probe resistance system (Model No: RTS-9, Probes Tech, Guangzhou, China).

\section{Results and discussion}

Microstructural characterization of the films

Figure 1 shows the XRD patterns of the films. The wurtzite $\mathrm{ZnO}$ is the only XRD detectable phase of the films (JCPDS card No: 36-1451). Obvious $c$-orientation decreased as increasing $\mathrm{Sm}$ content is observed for the films with the Sm contents of $0,0.25$, and 0.50 at.\%. This $c$-orientation transforms to a weak $a$-orientation as the $\mathrm{Sm}$ content is over 0.75 at. $\%$. The formation of the $c$-orientation could be associated to the rapid heating rate in the calcination process and the lattice parameter matching between the films and substrate [17]. Whereas the transformation to $a$-orientation could be related to the slowdown of the $\mathrm{ZnO}$ crystallization (the decrease of the crystallinity) and the variation of lattice parameter resulted from Sm-doping. Crystallites size $(D)$ was obtained according to the Scherrer's equation

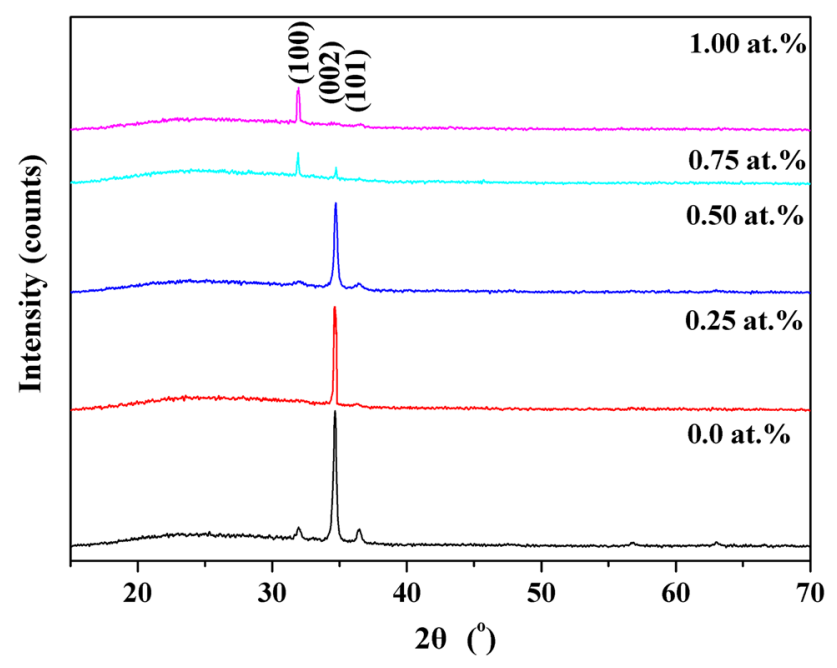

Fig. 1 XRD patterns of the films deposited from solution with various $\mathrm{Sm}$ contents
$D=0.9 \frac{\lambda}{\beta \cos \theta}$

where $\lambda$ is the $\mathrm{X}$-ray wavelength, $\beta$ the full width at half maximum of the considered peak and $\theta$ is the Bragg angle. Since wurtzite $\mathrm{ZnO}$ is a hexagonal crystal, the lattice parameters of the films can be calculated with XRD data analysis by following equation:

$\frac{a^{2}}{d^{2}}=\frac{4}{3}\left(h^{2}+h k+k^{2}\right)+\frac{a^{2}}{c^{2}} l^{2}$

The calculated lattice parameters and average particle sizes of the films are listed in Table 1. The average particle size overall decreases as increasing Sm content, which could be ascribed to the interference of the $\mathrm{Sm}$ cation to the $\mathrm{ZnO}$ crystal growth. This interference effect could be associated with the crystal lattice distortion due to the larger ionic radius of $\mathrm{Sm}^{3+}(1.04 \AA)$ compared with $\mathrm{Zn}^{2+}(0.74 \AA)$. The lattice expands as the increase of Sm content, which is also due to larger ion radius of $\mathrm{Sm}^{3+}$ cation than that of $\mathrm{Zn}^{2+}$ cation and the decrease of the crystallinity.

Figure 2 shows the SEM micrographs of the films. The films are composed of small hexagonal and granular morphology particles and some larger hexagonal rodlike particles. The hexagonal granular particles in the films with $\mathrm{Sm}$ content of $0-0.50$ at.\% could also have rodlike morphology and is approximately perpendicular to the substrate and the rodlike morphology and its disappearance with Sm doping could correspond to the $c$ orientation and $a$-orientation, respectively. Average particle size decreases with increasing Sm content. This is consistent with the results calculated with the XRD data analysis. The grains appear larger than average particle size than the results estimated with the XRD data analysis, which could imply that the nanoparticles in the films are polycrystalline. The measured film thicknesses are in a range of $\sim 835-920 \mathrm{~nm}$ as listed in Table 1.

Optical property of the films

Figure $3 \mathrm{a}, \mathrm{b}$ shows the transmittance $(T)$ and reflectance $(R)$ spectra of the $\mathrm{ZnO}: \mathrm{Sm}$ films. Their average values in the wavelength range of $280-840 \mathrm{~nm}$ are listed in Table 2. The average transmittances are in the range of $\sim 59.4-74.2 \%$. They first increase and then decrease with increasing $\mathrm{Sm}$ content and show the maximum as Sm content equals 0.75 at.\% (Fig. 3a). The increase of transmittance with respect to the pure $\mathrm{ZnO}$ film may be related to the well-known Moss-Burstein effect and the decrease of crystallinity. Moreover, the light adsorption 
Table 1 Lattice parameter, average particle size and thickness of the $\mathrm{ZnO}$ films deposited from solutions with various designed $\mathrm{Sm}$ contents (at.\%)

\begin{tabular}{|c|c|c|c|c|c|c|c|}
\hline \multirow[t]{2}{*}{ Sm content } & \multicolumn{2}{|c|}{ Lattice parameter $(\AA)$} & \multicolumn{4}{|c|}{ Particle size (nm) } & \multirow[t]{2}{*}{ Thickness (nm) } \\
\hline & $a$ & $c$ & $(100)$ & $(002)$ & $(101)$ & Average & \\
\hline 0 & 3.2309 & 5.1718 & 22.0 & 31.6 & 23.9 & 25.8 & 920 \\
\hline 0.25 & 3.2342 & 5.1741 & - & 36.0 & 16.2 & 26.1 & 895 \\
\hline 0.50 & 3.2365 & 5.1766 & 14.4 & 30.1 & 14.3 & 19.6 & 885 \\
\hline 0.75 & 3.2382 & 5.1802 & 22.1 & 19.8 & 21.1 & 21.0 & 865 \\
\hline 1.00 & 3.2327 & 5.1830 & 24.9 & 18.0 & 16.4 & 19.8 & 835 \\
\hline
\end{tabular}
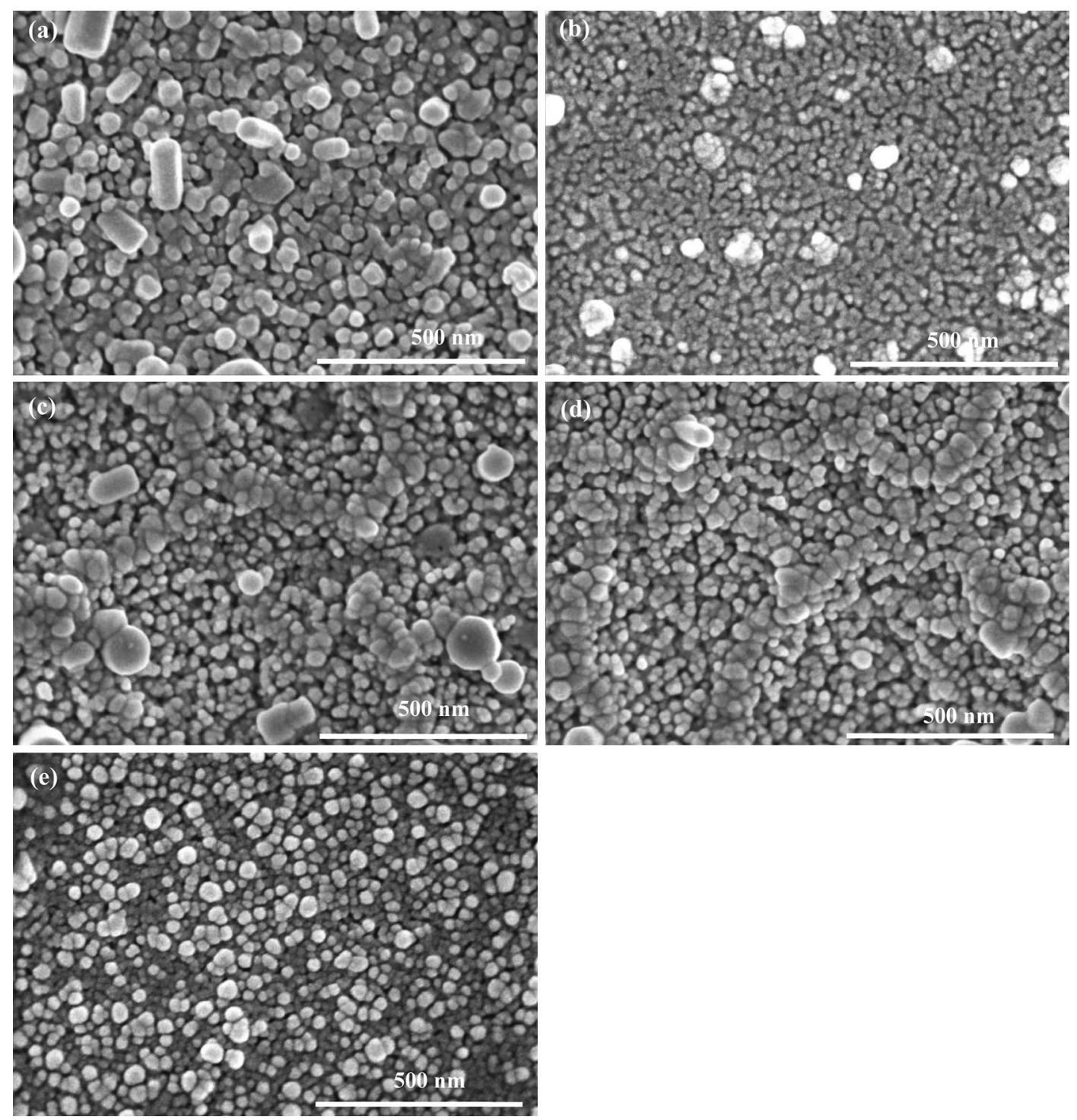

Fig. 2 SEM micrographs of the films deposited from solution with Sm contents of a 0 at. $\%, \mathbf{b} 0.25$ at. $\%$, c 0.5 at. $\%$, d 0.75 at. $\%$ and e 1.0 at. $\%$

edge first blue-shifts and then red-shifts with the increase of $\mathrm{Sm}$ content. Wurtzite $\mathrm{ZnO}$ has a direct band gap, so that the optical band gap $\left(E_{\mathrm{g}}\right)$ can be calculated with Tauc's relationship [18]: $(\alpha h v)^{2}=\mathrm{C}\left(h v-E_{\mathrm{g}}\right)$

where $h v$ is photon energy, $C$ is a constant, and $\alpha$ is absorption coefficient. The $\alpha$ can be calculated by equation [19]: 

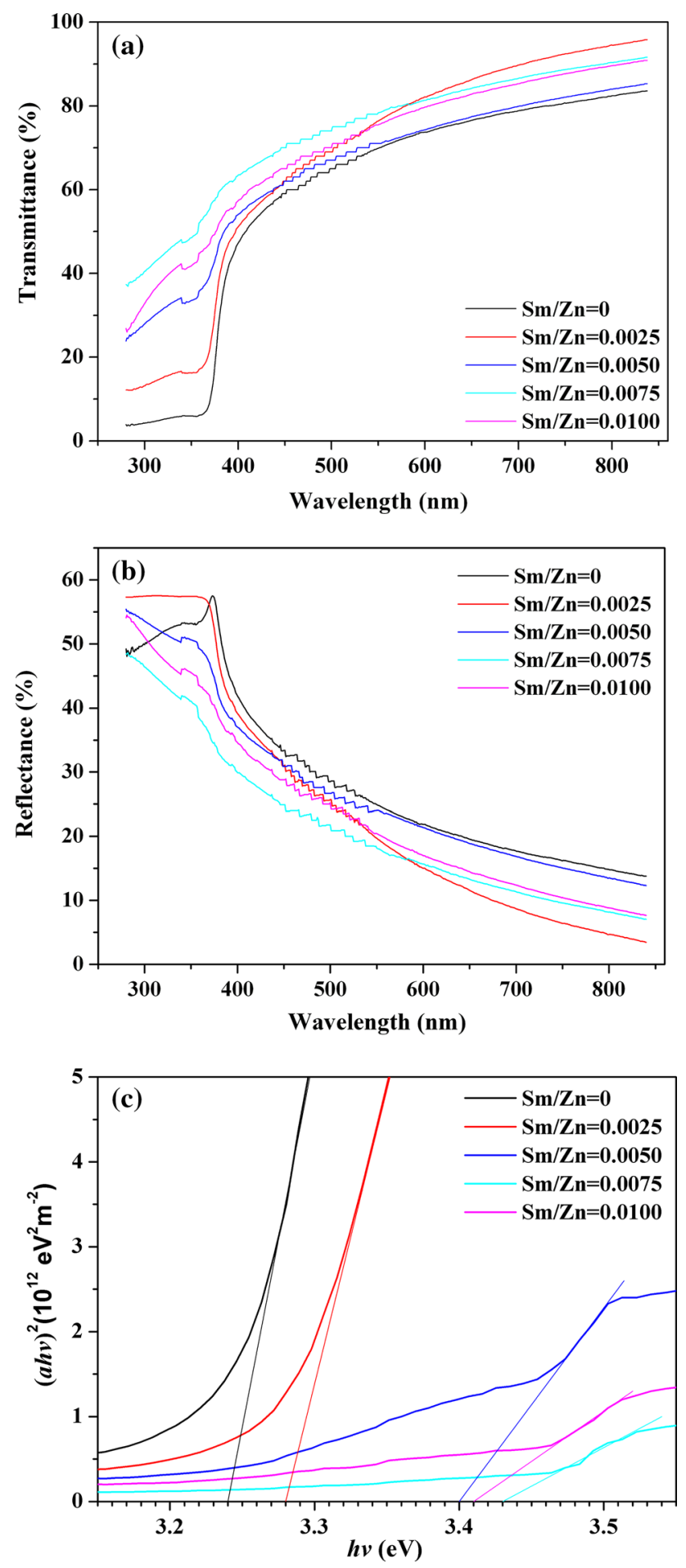

Fig. 3 a Transmittance $(T)$, b absorbance $(A)$, c graphs of $(\alpha h v)^{2}$ vs. photon energy $h v$

$\alpha=\frac{1}{d} \ln \frac{1-R}{T}$

where $d$ is the film thickness. Figure 3c shows the graphs of $(\alpha h v)^{2}$ versus photon energy $h v$. The linear dependences of $(\alpha h v)^{2}$ on $h v$ at higher photon energies indicate that the films are essentially direct-transition-type semiconductors. The straight-line portion of the curve, when extrapolated to zero, gives the optical band gap $E_{\mathrm{g}}$. The estimated $E_{\mathrm{g}}$ are in the range of $\sim 3.24-3.43 \mathrm{eV}$ (Table 2). Maximal widening $(0.19 \mathrm{eV})$ is achieved as $\mathrm{Sm}$ content equals 0.75 at.\%. This widening is larger than the reported $0.018 \mathrm{eV}$ and $0.04 \mathrm{eV}$ resulted from $\mathrm{Al}$ doping of 2-3 at.\% [20, 21] and near $0.21 \mathrm{eV}$ due to Er dopings of 0.6 at.\% [19]. The band gap widening with respect to the pure $\mathrm{ZnO}$ film may be the well-known Moss-Burstein shift [13-16, 19]. In addition, the band gap is also associated with the particle size and lattice parameter. The decrease of the average particle size as the increase of Sm content can widen the band gap due to quantum refinement effect. Whereas the lattice expansion as the increase of Sm content can narrow the band gap due to decreased interaction between atoms.

Optical constants, refractive index $(n)$ and extinction coefficient $(k)$, of the pure and doped $\mathrm{ZnO}$ films can be calculated on basis of relations $[19,22]$,

$n=\frac{1+R^{1 / 2}}{1-R^{1 / 2}}$

$k=\frac{\alpha \lambda}{4 \pi}$

Their variations with incident photon $h v$ are shown in Fig. 4. The $n$ and $k$ values first decrease and then increase as increasing Sm content, which is consistent with the variations of the $R$ and $A$. In addition, the $n$ and $k$ values are also related with the lattice parameter [22]. The dielectric constant $(\varepsilon)$ of the films are determined with the relation $[19,22]$.

$\varepsilon=\varepsilon_{r}+\mathrm{i} \varepsilon_{i}=(n+\mathrm{i} k)^{2}$

where $\varepsilon_{\mathrm{r}}$ is the real part and is the normal dielectric constant, $\varepsilon_{\mathrm{i}}$ is the imaginary part and represents the dielectric loss. The variations of the $\varepsilon_{\mathrm{r}}$ and $\varepsilon_{\mathrm{i}}$ with incident photon $h v$ are shown in Fig. 5 and are also mainly dependent on the light absorption of the films. In addition, the $\varepsilon_{r}$ and $\varepsilon_{\mathrm{i}}$ should also be associated with the lattice parameter and particle size. In general, larger lattice parameter (low crystallinity) results in smaller light absorption and so smaller $\varepsilon_{\mathrm{r}}$ and $\varepsilon_{\mathrm{i}}$, while single-domain size leads to largest coercive field and so largest $\varepsilon_{\mathrm{r}}$ and $\varepsilon_{\mathrm{i}}$, and smaller particle size leads to larger domain wall concentration and so larger $\varepsilon_{\mathrm{r}}$ and $\varepsilon_{\mathrm{i}}$.

Figure 6 illustrates the photoluminescence spectra of the $\mathrm{ZnO}$ : Sm films. The strong emission peaks centered at $\sim 386$ and $\sim 494 \mathrm{~nm}$ are observed. The emission intensities overall first obviously increase as increasing Sm content to 0.5 at.\% and then decrease as further increasing Sm content. In general, smaller particle size corresponds a 
Table 2 The average values of optical parameters in the range of $280-840 \mathrm{~nm}$, band gap energy $\left(E_{\mathrm{g}}\right)$ of the $\mathrm{ZnO}: \mathrm{Sm}$ films

\begin{tabular}{lllllllc}
\hline Sm content (at.\%) & $T(\%)$ & $R(\%)$ & $E_{\mathrm{g}}(\mathrm{eV})$ & $n$ & $k \times 10^{-3}$ & $\varepsilon_{r}$ & $\varepsilon_{\mathrm{i}} \times 10^{-2}$ \\
\hline 0 & 59.4 & 29.0 & 3.24 & 3.6 & 12.4 & 14.8 & 13.8 \\
0.25 & 67.9 & 24.4 & 3.28 & 3.2 & 6.3 & 14.9 & 7.6 \\
0.50 & 65.8 & 27.4 & 3.40 & 3.4 & 4.3 & 13.4 & 3.7 \\
0.75 & 74.2 & 21.1 & 3.43 & 2.8 & 2.5 & 9.0 & 1.8 \\
1.00 & 70.8 & 23.6 & 3.41 & 3.1 & 3.2 & 11.0 & 2.6 \\
\hline
\end{tabular}
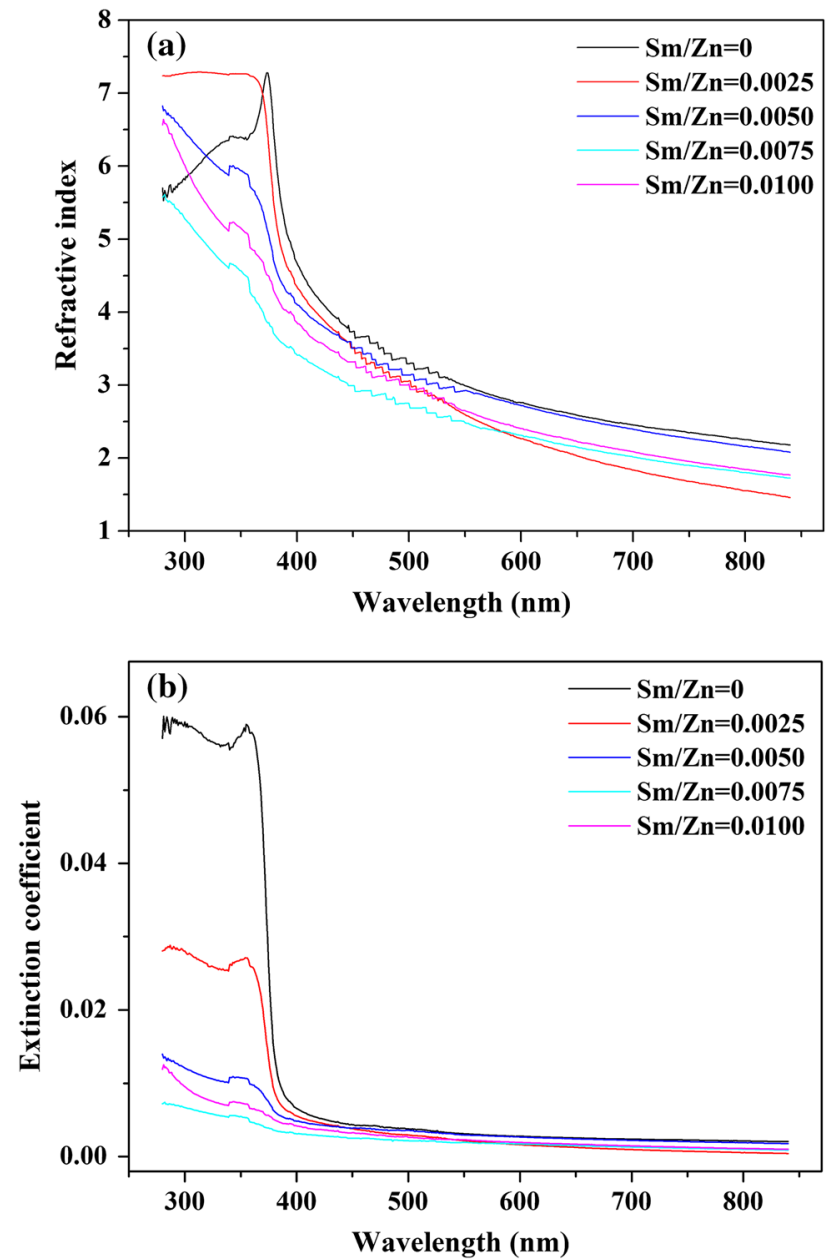

Fig. 4 a Refractive index and b extinction coefficient of the films with various $\mathrm{Sm}$ contents

larger specific surface area and thereby leading to larger emission intensity, however too small particle size leads to large light scattering that decreasing emission intensity. Thus, the variation of the emission intensity with $\mathrm{Sm}$ content could be ascribed to the variation of the average particle size with $\mathrm{Sm}$ content. The emissions centered at $\sim 386 \mathrm{~nm}(\sim 3.21 \mathrm{eV})$ could be near band gap emission [23] or band edge emission [24]. The emissions centered at $\sim 494 \mathrm{~nm}(\sim 2.51 \mathrm{eV})$ could be related to the energy interval from the $\mathrm{Zn}$ interstitial to the $\mathrm{Zn}$ vacancy level $(\sim 2.6 \mathrm{eV}[25,26])$.
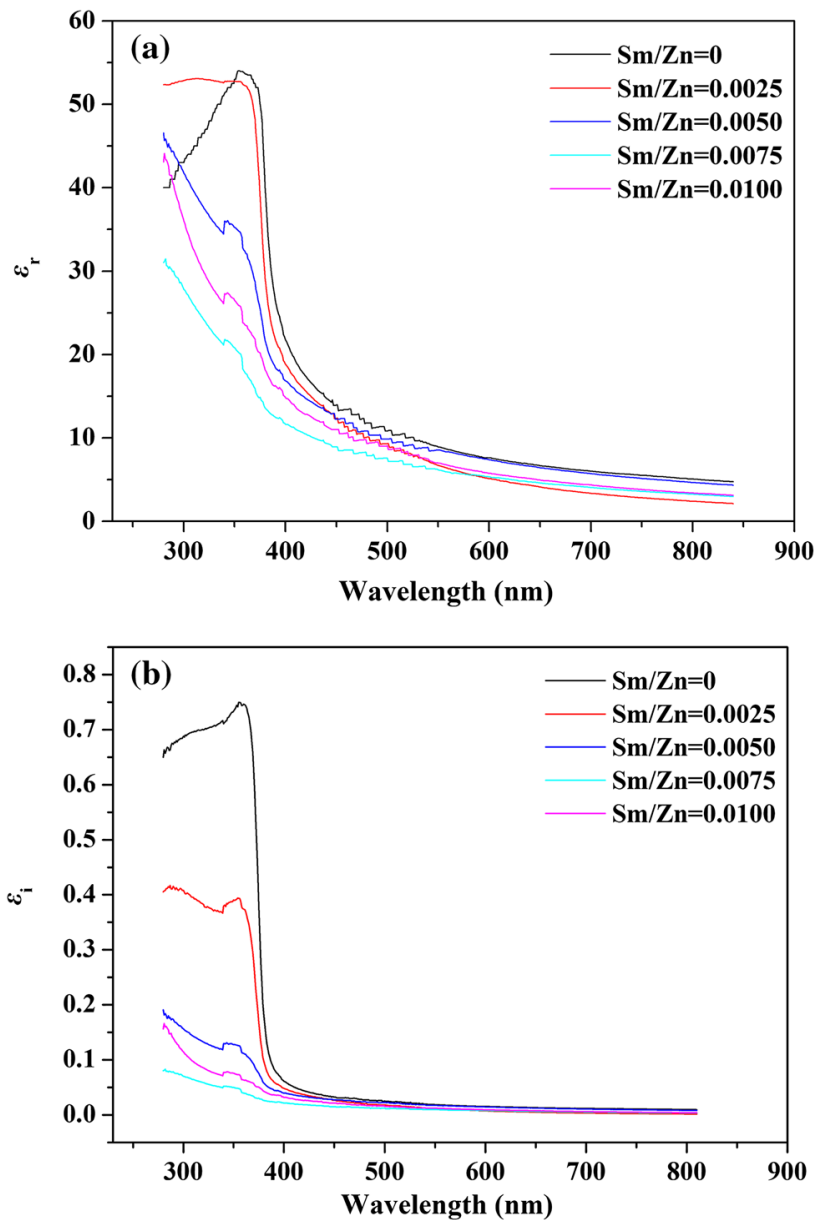

Fig. 5 a Real part and $\mathbf{b}$ imaginary part of dielectric constant of the $\mathrm{ZnO}$ : Sm films vs. incident photon $h v$

\section{Electrical property}

The variation of electrical resistivity with Sm content is shown in Fig. 7. The resistivity of the films first obviously decreases from $\sim 5.61 \times 10^{-2} \Omega \mathrm{cm}$ to $\sim 0.28 \times 10^{-2} \Omega \mathrm{cm}$ and increases to $\sim 0.88 \times 10^{-2} \Omega \mathrm{cm}$ with the increase of $\mathrm{Sm}$ content. The film with Sm-content of 0.75 at.\% shows a minimal resistivity. The increase in electrical conductivity could originate from the increase of the large carrier concentration introduced by trivalent $\mathrm{Sm}^{3+}$ cation. This also might imply that the films are n-type conductive. The resistivity of the $\mathrm{ZnO}$ films is associated with preparation method 


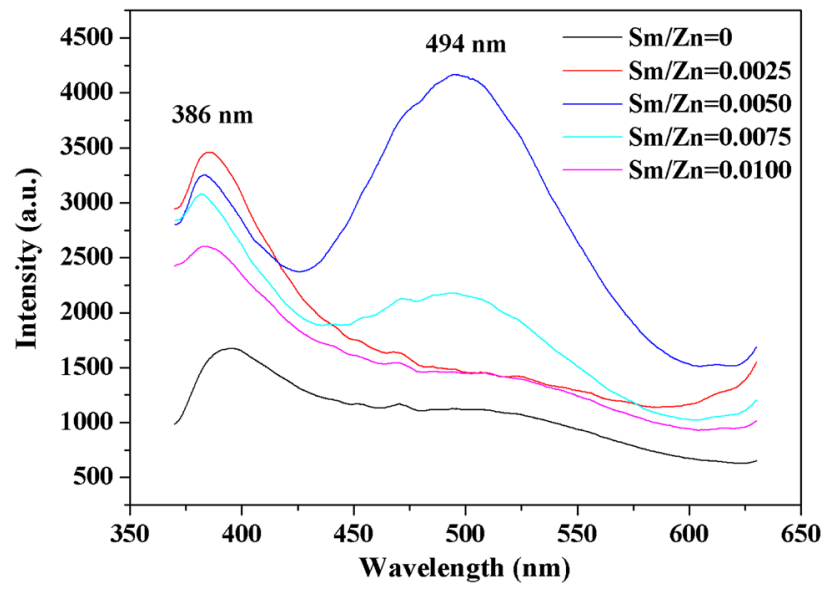

Fig. 6 Photoluminescence spectra of the $\mathrm{ZnO}$ : Sm films

and processing parameter. A resistivity of $6.44 \times 10^{-2}$ to $4.44 \times 10^{-5} \Omega \mathrm{cm}$ is reported for RF magnetron sputtered $\mathrm{ZnO}$ : Co films [27]. Another RF magnetron sputtered $\mathrm{ZnO}: \mathrm{Ga}$ film showed a resistivity of $\sim 5.3 \times 10^{-2}$ to $8.4 \times 10^{-4} \Omega \mathrm{cm}$ [28]. A ZnO film deposited by ultra-high frequency spraying process at $480{ }^{\circ} \mathrm{C}$ doped with $1.9 \%$ copper and annealed for $10 \mathrm{~h}$ at $700{ }^{\circ} \mathrm{C}$ exhibits a resistivity as high as $5.6 \times 10^{12} \Omega \mathrm{cm}[29]$.

The deterioration of the optical transmittance and electrical conductivity of the films with excessively increasing Sm content could be ascribed to the electron-impurity interaction and the columbic interaction between the carriers [24].

\section{Conclusions}

The effects of Sm doping on the microstructure and optical and electrical properties of the $\mathrm{ZnO}$ films were investigated. With increasing Sm content, the average particle size decreased, and the transmittance in the range of UVvisible light and band gap was first increased and then decreased. The Sm content of 0.75 at \% led to maximal transmittance and widened band gap of from $3.24 \mathrm{eV}$ of the pure film to $3.43 \mathrm{eV}$. Moreover, the resistivity of the films was in the range of $0.28-6.51 \times 10^{-2} \Omega \mathrm{cm}$ and also first decreased and then increased with increasing Sm content. The decrease of resistivity with the increase of carrier concentration resulted from Sm doping indicated that the films are n-type conductive. Furthermore, the films showed strong near band gap emission centered at $386 \mathrm{~nm}$ and blue-green emission centered at $494 \mathrm{~nm}$. The refractive index, extinction coefficient, optical conductivity, and dielectric constant of the films were calculated with the transmittance and reflectance spectra. Improved optical and electrical properties by Sm doping may be of significance

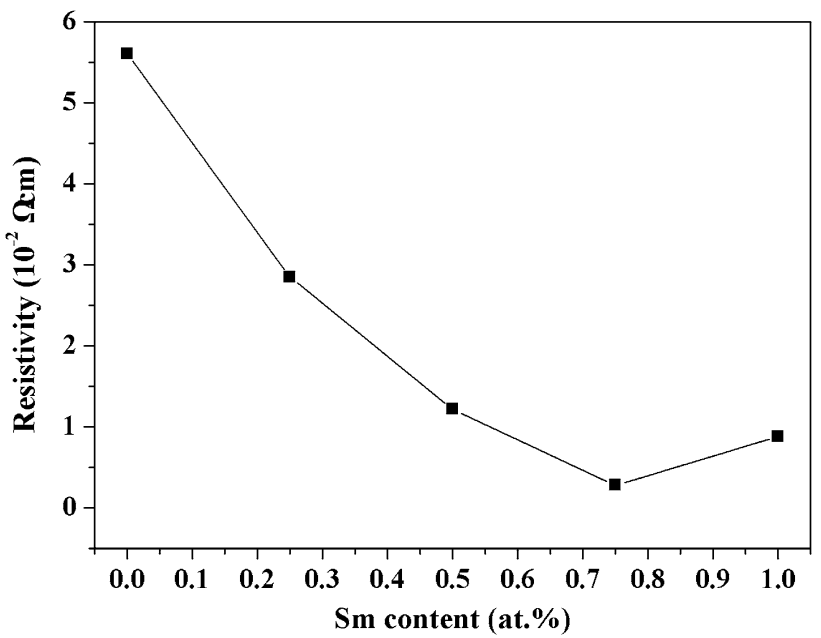

Fig. 7 Electrical resistivity of the films vs. Sm contents

to the optical and electrical applications of the Sm-doped $\mathrm{ZnO}$ materials.

Open Access This article is distributed under the terms of the Creative Commons Attribution License which permits any use, distribution, and reproduction in any medium, provided the original author(s) and the source are credited.

\section{References}

1. Polla, D.L., Muller, R.S., White, R.M.: Integrated multisensor chip. IEEE Electron Device Lett. 7, 254-256 (1996). doi:10. 1109/EDL.1986.26363

2. BeekE, W.J., Wienk, M.M., Janssen, R.A.J.: Hybrid solar cells from regioregular polythiophene and $\mathrm{ZnO}$ nanoparticles. Adv. Funct. Mater. 16, 1112-1116 (2006). doi:10.1002/adfm. 200500573

3. Wang, Z.-L., Song, J.-H.: Piezoelectric nanogenerators based on zinc oxide nanowire arrays. Science 312, 242-246 (2006). doi:10. 1126/science. 1124005

4. Wang, J.-X., Sun, X.-W., Yang, Y., Huang, H., Lee, Y.C., Tan, O.-K., Vayssieres, L.: Hydrothermally grown oriented $\mathrm{ZnO}$ nanorod arrays for gas sensing applications. Nanotech 17, 4995-4998 (2006). doi:10.1088/0957-4484/17/19/037

5. Liu, H.-Y., Kong, H., Ma, X.-M., Shi, W.-Z.: Microstructure and electrical properties of $\mathrm{ZnO}$-based varistors prepared by highenergy ball milling. J. Mater. Sci. 42, 2637-2642 (2007). doi:10. 1007/s10853-006-1350-7

6. Terasako, T., Song, H., Makino, H., Shirakata, S., Yamamoto, T.: Temperature dependence of electrical properties of Ga-doped $\mathrm{ZnO}$ films deposited by ion plating with DC arc discharge. Thin Solid Films 528, 19-25 (2013). doi:10.1016/j.tsf.2012.07.140

7. Nunes, P., Fernandes, B., Fortunan, E., Vilarinlo, P., Martins, R.: Performances presented by zinc oxide thin films deposited by spray pyrolysis. Thin Solid Films 337, 176-179 (1999). doi:10. 1016/S0040-6090(98)01394-7

8. Reddy, K.T.R., Miles, R.W.: Growth and characterization of sprayed ZnO: Ga thin films. J. Mater. Sci. Lett. 17, 279-281 (1998). doi:10.1023/A:1006569203107

9. Lin, S.-S., Huanga, J.-L., Sajgalik, P.: The properties of Tisubstituted $\mathrm{ZnO}$ films deposited by simultaneous RF and DC 
magnetron sputtering. Surf. Coat. Tech. 191, 286-292 (2005). doi:10.1016/j.surfcoat.2004.03.021

10. Misra, K.P., Shukla, R.K., Srivastava, A., Srivastava, A.: Blueshift in optical band gap in nanocrystalline $\mathrm{Zn}_{1-\mathrm{x}} \mathrm{Ca}_{\mathrm{x}} \mathrm{O}$ films deposited by sol-gel method. Appl. Phys. Lett. 95(3), 031901-031905 (2009). doi:10.1063/1.3184789

11. Das, A.K.: Misra P and Kukreja L.M.: Effect of Si doping on electrical and optical properties of $\mathrm{ZnO}$ thin films grown by sequential pulsed laser deposition. J. Phys. D Appl. Phys. 42, 165405-165411 (2009). doi:10.1088/0022-3727/42/16/165405

12. Minami, T., Yamamoto, T., Miyata, T.: Highly transparent and conductive rare earth-doped $\mathrm{ZnO}$ thin films prepared by magnetron sputtering. Thin Solid Films 366, 63-68 (2000). doi:10.1016/ S0040-6090(00)00731-8

13. Wu, C.-G., Shen, J., Ma, J., Wang, S.-P., Zhang, Z.-J., Yang, X.L.: Electrical and optical properties of molybdenum-doped $\mathrm{ZnO}$ transparent conductive thin films prepared by dc reactive magnetron sputtering. Semicond. Sci. Technol. 24, 125012-125017 (2009). doi:10.1088/0268-1242/24/12/125012

14. Lin, Y.-C., Wang, B.-L., Yen, W.-T., Ha, C.-T., Peng, C.: Effect of process conditions on the optoelectronic characteristics of ZnO:Mo thin films prepared by pulsed direct current magnetron sputtering. Thin Solid Films 518, 4928-4934 (2010). doi:10. 1016/j.tsf.2010.03.007

15. Fang, Z.-B., Tan, Y.-S., Gong, H.-X., Zhen, C.-M., He, Z.-W., Wang, Y.-Y.: Transparent conductive Tb-doped $\mathrm{ZnO}$ films prepared by rf reactive magnetron sputtering. Mater. Letters 59, 2611-2614 (2005). doi:10.1016/j.matlet.2005.02.062

16. Kumari, V., Kumar, V., Malik, B.P., Mehra, R.M., Mohan, D.: Nonlinear optical properties of erbium doped zinc oxide (EZO) thin films. Opt. Commun. 285, 2182-2188 (2012). doi:10.1016/j. optcom.2011.12.094

17. He, H.Y., Yu, H.Y.: Enhancement in optical transmission of $\mathrm{ZnO}: \mathrm{Al}$ film by c-orientation arrayed growth. Int. J. Mat. Res. 102(5), 556-559 (2011). doi:10.3139/146.110414

18. Chen, J.L., Chen, D., He, J.J., Zhang, S.Y., Chen, Z.H.: The microstructure, optical, and electrical properties of sol-gel-derived Sc-doped and Al-Sc co-doped ZnO thin films. Appl. Surf. Sci. 255, 9413-9419 (2009). doi:10.1016/j.apsusc.2009.07.044

19. Pathan, H.M., Desai, J.D., Lokhande, C.D.: Modified chemical deposition andphysico-chemical properties of copper sulphide
$\left(\mathrm{Cu}_{2} \mathrm{~S}\right)$ thin films. Appl. Surf. Sci. 202, 47 (2002). doi:10.1016/ S0169-4332(02)00843-7

20. Korake, P.V., Dhabbe, R.S., Kadam, A.N., Gaikwad, Y.B., Garadkar, K.M.: Highly active lanthanum doped $\mathrm{ZnO}$ nanorods for photodegradation of metasystox. J. Photochem. Photobiol., B 130, 11-19 (2014). doi:10.1016/j.jphotobiol.2013.10.012

21. Chaki, S.H., Deshpande, M.P., Tailor, J.P.: Characterization of $\mathrm{CuS}$ nanocrystalline thin films synthesized by chemical bath deposition and dip coating techniques. Thin Solid Films 550, 291-297 (2014). doi:10.1016/j.tsf.2013.11.037

22. Luo, Z.-D., Huang, Y.-D.: Qualitative analysis of relationship between refractive index and atomic parameters of solid materials. J. Rare Earths 22, 486-488 (2004)

23. Wraback, M., Shen, H., Liang, S., Gorla, C.R., Lu, Y.: High contrast, ultrafast optically addressed ultraviolet light modulator based upon optical anisotropy in $\mathrm{ZnO}$ films grown on R-plane sapphire. Appl. Phys. Lett. 74, 507 (1999). doi:10.1063/1.124223

24. Schaadt, D.M., Brandt, O., Ghosh, S., Flissikowski, T., Jahn, U., Grahn, H.T.: Polarization-dependent beam switch based on an M-plane GaN/AlN distributed Bragg reflector. Appl. Phys. Lett. 90, 231117 (2007). doi:10.1063/1.2747189

25. Xu, P.-S., Sun, Y.-M., Shi, C.-S., Xu, F.-Q., Pan, H.-B.: The electron structures of $\mathrm{ZnO}$ and its defects. Sci. Chin. A. 31(4), 358-365 (2001)

26. Lin, B.-X., Fu, Z.-X.: Green luminescent center in undoped zinc oxide films deposited on silicon substrates. Appl. Phys. Lett. 79. 943-945 (2001). doi:10.1063/1.1394173

27. Güner, S., Gürbüz, O., Çalışkan, S., Nuzhdin, V.I., Khaibullin, R., Öztürk, M., Akdoğan, N.: The structural and magnetic properties of $\mathrm{Co}^{+}$implanted $\mathrm{ZnO}$ films. Appl. Surf. Sci. 310, 235-241 (2014). doi:10.1016/j.apsusc.2014.03.085

28. Chang, S.H., Cheng, H.-M., Tien, C.-L., Lin, S.-C., Chuang, K.P.: Optical, electrical and mechanical properties of Ga-doped $\mathrm{ZnO}$ thin films under different sputtering powers. Opt. Mater. 38, 87-91 (2014). doi:10.1016/j.optmat.2014.10.004

29. Labeau, M., Rey, P., Deschanvres, J.L., Joubert, J.C., Delabouglise, G.: Thin films of high-resistivity zinc oxide produced by a modified CVD method. Thin Solid Films 213, 94 (1992). doi:10.1016/0040-6090(92)90480-Y 